\title{
PIEZAS INÉDITAS DEL PATRIMONIO DE LA ABADÍA DEL SACRO MONTE EN GRANADA.
}

\author{
JOSÉ ANTONIO PEINADO GUZMÁN \\ ISAAC PALOMINO RUIZ \\ Universidad de Granada \\ Resumen
}

La abadía del Sacro Monte de Granada, a lo largo de su existencia, se convirtió en un centro religioso, académico, cultural y artístico de enorme trascendencia. Los siglos de pervivencia, desde este último aspecto, han permitido que la institución albergue y conserve en su interior un importante patrimonio escultórico, pictórico, textil, mobiliario... En este artículo extraemos y sacamos a la luz un conjunto de piezas desconocidas, de lo más destacado de la escultura de la institución sacromontana, que vienen a completar los estudios que sobre esta materia ya existían.

Palabras clave
Granada, Escultura, Iconografía, Sacro Monte, Edad Moderna.

\section{UNPUBLISHED PIECES OF HERITAGE OF THE ABBEY OF SACROMONTE IN GRANADA}

Abstract
The Abbey of the Monte Sacro in Granada, throughout its existence, became a religious, academic, cultural and artistic center of enormous significance. Centuries of survival, since this last aspect, have allowed the institution to hostel and save inside an important heritage, sculpture, painting, textile, furniture... In this article we extract and took out a set of parts unknown, highlights from the sculpture of the sacromontana institution, coming to complete studies that already existed on this matter.

Keywords

Granada, Sculpture, Iconography, Sacro Monte, Modern Age. 


\section{Introducción.}

En el mes de febrero de 1609, a instancias del prelado don Pedro de Castro Cabeza de Vaca y Quiñones, se colocaría la primera piedra de la abadía del Sacro Monte a las afueras de la ciudad de Granada. En el monte Valparaíso del antiguo reino nazarí se erigía de este modo un amplio complejo compuesto por la citada abadía, su iglesia y el colegio-seminario bajo la advocación de San Dionisio Areopagita ${ }^{1}$.

Toda aquella construcción suponía una conmemoración de los famosos descubrimientos que se empezaron a producir a partir de 1595. Desde esa fecha hasta 1599, fueron apareciendo los conocidos libros plúmbeos, un total de veintidós, en los que se narraban una serie de contenidos doctrinales, a modo de revelación divina, como si de un quinto evangelio se tratase. En los mismos se exponía una visión sincrética entre el cristianismo y el islam, en un contexto complicado para los musulmanes, toda vez que recientemente había acontecido la Guerra de las Alpujarras. La intencionalidad de aquellos libros era coadyuvar a una convivencia pacífica entre ambos credos. Parece ser que los mismos fueron escritos por moriscos de alto rango social, concretamente se cree que serían Miguel de Luna y Álvaro del Castillo. Finalmente, todos estos documentos serían condenados por la Santa Sede en 1682.

Así pues, a partir de toda esta historia, el arzobispo don Pedro de Castro, principal adalid y defensor de los libros plúmbeos y de sus contenidos, creará la institución sacromontana. La abadía del Sacro Monte, con el paso de los siglos, terminará por convertirse en un centro neurálgico no solamente religioso, sino también académico y cultural. Es en este último aspecto donde nos vamos a centrar en este artículo. Concretamente valoraremos su dimensión artística y, dentro de ella, el importante patrimonio escultórico que alberga en su interior.

De este modo, una vez vistos estos prolegómenos, sin mayores dilaciones, pasaremos a analizar una serie de piezas desconocidas hasta ahora, que componen la ingente herencia abacial.

Una obra que tradicionalmente se ha atribuido a las gubias de Torcuato Ruiz del Peral, se contempla en el retablo de la Inmaculada de la iglesia abacial del Sacro Monte ${ }^{2}$. Se ha podido documentar que la escultura, realmente, fue realizada por Pedro Valero entre $1763 \mathrm{y}$ 1765. Como curiosidad, la talla fue pagada con raciones de comida y hogazas de pan.

\footnotetext{
"Con este motivo se dijo estar ya comenzados los retablos colaterales que se hacian a costa de la deuocion y limosna de los señores que la ofrecieron, y se confirio sobre las ymagenes de la Purissima Concepcion y Señor San José, que se auian de colocar en ellos, para cuio costo no se vian fondos en la Comunidad, y que auiendo hablado con Don Pedro Valero los señores comisionados para los retablos, se conuenia por su bondad de Genio a la maior equidad, y aduitrios que juzgasse el Cauildo de quien tomaria lo que se le diesse, sin poner precio a su trabajo; y se determino que desde luego comienze, y se le asista diariamente con dos raciones y dos hogazas, lleuando la quenta en la cozina para regular al fin de todo los correspondientes valores".

"Y se determino, se le den diariamente las dos hogazas y dos raciones diarias, que se dieron mas de un año a Don Pedro Valero a quien se encargaron las dos ymagenes de
}

1 Como bibliografía básica acerca del Sacro Monte extraemos, según criterio cronológico, la siguiente: Centurión, s/f; 1632; Serna Cantoral, 1706; Ramos, 1883; Royo Campos, 1951; 1954; 1958; 1960. Pita Andrade, 1974; Cabanelas, 1965; 1974: 34-40; Sánchez-Mesa Martín, 1974: 53-61; Hagerty, 1980; Bonet Correa, 1981: 4354; Bermúdez de Pedraza, 1989; Caro Baroja, 1992; Antolínez de Burgos, 1996; Martínez Medina, 1996; 1997: 3-22. Heredia Barnuevo, 1998; Martínez Medina, 1998: 349-379; Barrios Aguilera, 2000: 601-617; Justicia Segovia, 2000: 645-648; Martínez Medina, 2000: 619-644; 2002: 437-475; 2005: 119-155; Barrios Aguilera, 2006: 17-50; Benítez Sánchez-Blanco, 2006: 217-252; Martínez Medina, 2006: 79-112.

2 Gallego y Burín, 1987: 116, nota 172; Sánchez-Mesa Martín, 1974: 55; Martínez Justicia, 1996: 84-86; Sánchez-Mesa Martín, 1998: 275; León Coloma, 2005: 265; AA. VV. 2006: 279; López-Muñoz, 2008a: 89 y 9091; 2008b: 61; López-Guadalupe Muñoz, 2008: 312; Gómez Román, 2008: 356. 
Fig. 1. Inmaculada Concepcion de la Iglesia de la Abadía del Sacromonte. Pedro Tomás Valero, 1763-1765.

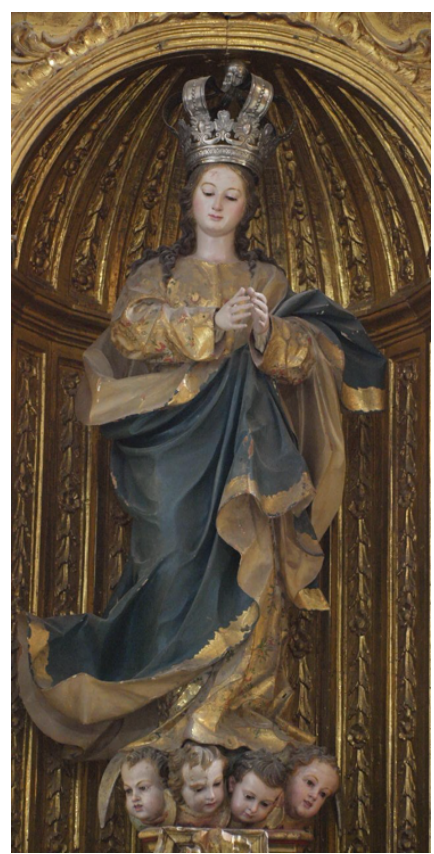

Nuestra Señora de la Concepcion, y señor san José, que se han de colocar en dichos dos retablos, las que esta para concluir antes del ymbierno siguiente, y que para tasar y regular su trabajo se encargue a sugeto inteligente pase a verlas, y despues se regulen los valores del pan y raciones que se le dieron"3.

En esta muestra apreciamos el influjo Diego de Mora, quien había sido a su vez preceptor de Vera Moreno, al que Valero estará íntimamente ligado. En este caso concreto, el rostro de la Virgen recuerda tanto al de la Virgen Sedente del convento del Santo Ángel Custodio, como a la Inmaculada de la clausura del convento de Santo Tomás de Villanueva, sendas esculturas atribuibles al menor de los Mora. Asimismo, los amplios vuelos del manto, se distancian un tanto de los cánones canescos, evocando trazas más propias del tipo sevillano, al esbozar esa forma trapezoidal.

Según esto, observamos la figura mariana sobre los característicos querubes, ubicados a sus pies. Las cuatro cabezas aladas de ángeles que se disponen en la base, destacan por su diferenciación. En lugar de repetir el mismo modelo para los distintos seres celestes, como se habitúa en estos minúsculos detalles, busca el detalle de diferirlos individualmente. Igualmente, se vislumbra la típica luna en creciente, con las puntas hacia abajo, observándose las mismas saliendo por ambos lados de la parte inferior de la talla. La Virgen se contempla de pie, erguida, adelantando su pie derecho levemente, a la par que el opuesto permanece en reposo. Sus manos hacen amago de unirse a la altura del pecho. Los dedos no llegan a juntarse por sus yemas. Los brazos se desplazan sutilmente hacia la derecha, de igual modo que lo hace la cabeza. La respectiva pose de piernas y brazos, genera el típico contraposto que desarrolla un mínimo movimiento en una iconografía que, por esencia, acostumbra a adolecer de dinamismo. Sobre su prominente cuello, distinguimos un rostro ovalado, de pequeña boca, nariz recta, hoyuelo en la barbilla, ojos grandes y rasgados con pestañas artificiales, y cejas sensiblemente arqueadas. Su cabello largo, castaño y notoriamente rizado, se dispone sobre sus espaldas, cayendo en mechones por el pecho. Resulta destacable el fino trabajo realizado en el pelo. Éste se abre a la altura de las mejillas, dejando su cara más despejada. Sus ojos entreabiertos y su mirada baja, nos muestran el típico semblante meditativo y orante característico de estas iconografías inmaculistas. En este sentido, el rostro

${ }^{3}$ Actas Capitulares, X, 22 de agosto de 1763, Archivo del Sacro Monte (A.S.M.), f. 223 vto.; Actas Capitulares, $X, 1$ de julio de 1765, A. S. M., f. 295 r. 


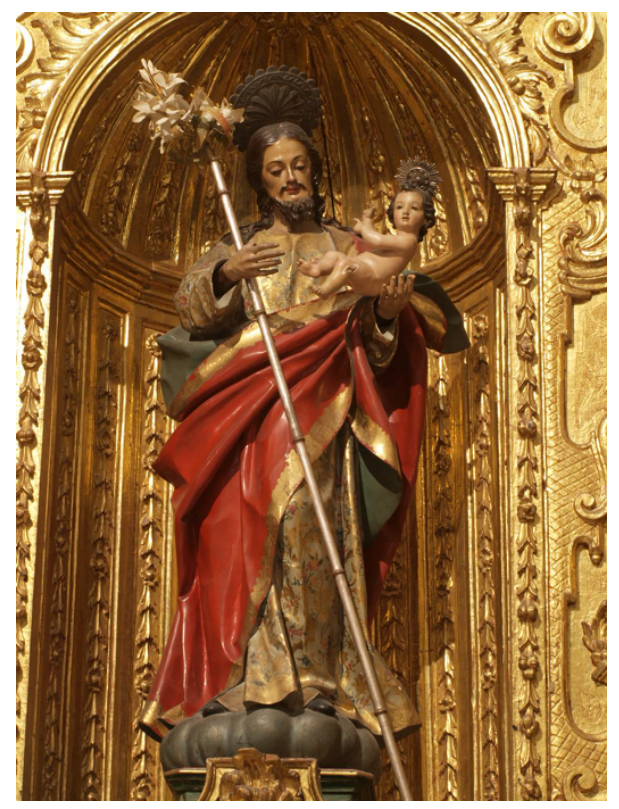

Fig. 2. San José de la Iglesia de la Abadía del Sacromonte. Pedro Tomás Valero, 1763-1765.

presenta un enorme parecido con el San Rafael de la parroquial de los Santos Justo y Pastor, obra del escultor Torcuato Ruiz del Peral. Su cabeza, finalmente, se adorna con corona real metálica.

La Virgen viste una lucida túnica decorada a base de motivos chinescos y labores vegetales, realizándose estas últimas mediante la técnica del picado de lustre. Los elementos florales se policroman con tonalidades rojizas, verdosas y amarillentas. Bajo las mangas, se vislumbran otras inferiores de color blanco que se ciñen al puño. Sobre sus espaldas se coloca el clásico manto azul, por cuyo borde recorre una bella cenefa en oro, elaborando la mencionada técnica del picado de lustre. El recogido de la prenda, aun siendo similar al tipo del Racionero, lo realiza de un modo peculiar que lo diferencia. Si bien se tercia de izquierda a derecha dejando caer el pico sobre el brazo izquierdo, el fleco opuesto también desciende sobre la misma extremidad. En lo referente al plegado de los paños, no son muy reseñables los plisados de la túnica. En cuanto a los del manto, éstos vienen determinados tanto por la posición de las piernas, como por los amplios vuelos de la prenda. Las ondulaciones se perciben suaves y profundas, algo más cortantes y acuciadas al recogerse la vestimenta por la cintura, y trazando líneas principalmente diagonales.

Aunque la obra se encuentra en un aceptable estado de conservación, se observan considerables desperfectos en la policromía de la túnica y el manto, así como en la frente de la figura femenina.

Como hemos visto en la referencia documental aportada, a la par que hiciera la imagen de la Inmaculada Concepción, el citado Pedro Tomás Valero realizaría para el retablo paralelo de la iglesia del Sacro Monte la talla de San José. Por tanto, nos encontramos ante una escultura que se data entre 1763 y $1765^{4}$. La misma nos ofrece un bello ejemplo de la tradicional iconografía del Pater Putatiuus. Se muestra al santo en pie, con la habitual actitud paternal y protectora, manifiesta en la mirada dulce y atenta que transmite, a la par que recogida y algo melancólica. El Niño, que se aprecia sostenido por su mano izquierda, no ofrece un acomodo muy logrado, más bien todo lo contrario, mal definido. Parece que el escultor, en su idea originaria, quisiese que el santo acunase al Infante con sendas manos, y no utilizar la siniestra para sostener la clásica vara de azucenas, como en la actualidad contemplamos. Asimismo, el Niño aparece desnudo, con su mirada al frente, señalando con la mano izquierda a San

${ }_{4}$ Actas Capitulares, X, 22 de agosto de 1763, A.S.M., f. 223 vto.; Actas Capitulares, X, 1 de julio de 1765, A. S. M., f. 295 r. 


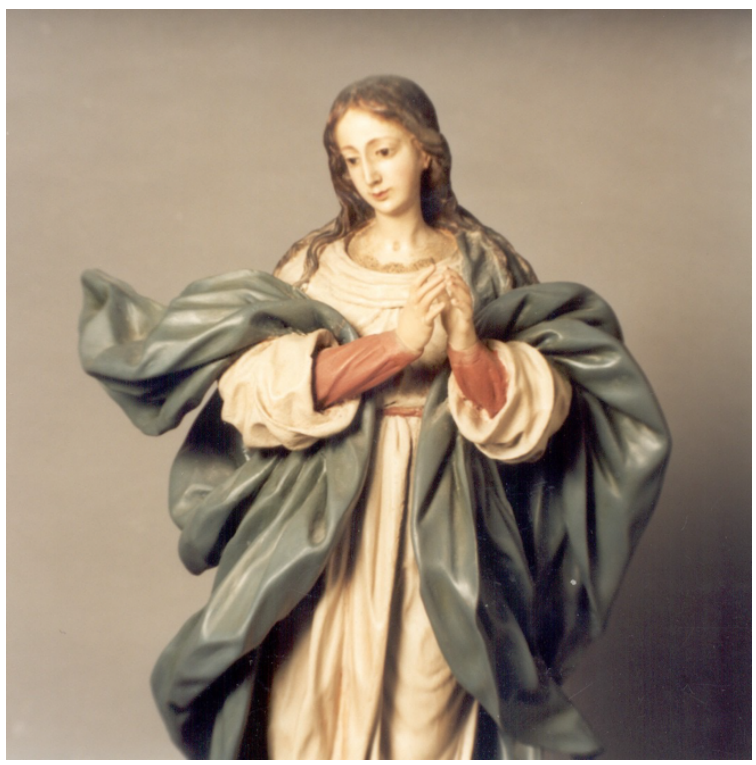

Fig. 3. Inmaculada Concepción de la Iglesia de la Abadía del Sacromonte. Pedro Duque Cornejo, c. 1725

José, mientras que deja la opuesta al aire. Cabe referir, en este sentido, que la figura infantil tampoco es muy destacable técnicamente. La escenografía de esta iconografía se sintetiza en la idea de la preponderancia de la imagen del Divino Infante frente a la humildad y sencillez del santo varón, al mismo tiempo que el Niño, señalando a José, parece querer resaltar la figura virtuosa del insigne esposo de la Virgen.

La talla, de tamaño natural, nos muestra la imagen de un hombre delgado, de rostro estilizado, con barba bífida, y en donde sus mechones aparecen bien trabajados. El bigote, más pintado que esculpido, no llega a unirse con la barba. Este último detalle es muy propio del taller de los Mora, algo que no es sorprendente por el aprendizaje directo que Valero recibió de Vera Moreno, uno de los grandes discípulos de Diego de Mora. Sus ojos almendrados, enmarcados por cejas levemente arqueadas, mantienen la mirada baja. La nariz es afilada y fina, a la par que se boca es pequeña. La marcada estructura ósea de cráneo y pómulos, nuevamente nos evocan las trazas escultóricas de los Mora, reinterpretadas en la lejanía de los estertores de la escuela granadina de escultura. Contemplamos, igualmente, su larga cabellera con mechones bien definidos y trabajados con suavidad. Ésta queda recogida hacia atrás, permitiéndonos ver el rostro despejado. Dos de sus mechones caen por sendos hombros.

El santo viste túnica talar, que se intuye estar ceñida bajo el manto. La misma, de color blanco crudo, casi ocre, se decora con estofa, conformando elementos vegetales. De igual modo, se aprecia la típica decoración a base de chinescos del siglo XVIII, utilizando tonalidades azuladas, rosáceas y verdosas. Tanto en mangas, cuello como en el filo de la prenda, se aprecia una lucida cenefa dorada utilizando la citada técnica del estofado. El manto, en tonalidad roja, posee galón perimetral en oro, realizando un bello picado de lustre. El forro del mismo también se vislumbra, policromado en tono grisáceo. Con respecto al plegado de las prendas, en lo referente a la túnica, se aprecia el mismo notoriamente plano, no muy abundante, pero anguloso. Destacables son los plisados que observamos a la altura del pecho, el que genera el avance de la pierna derecha, así como el que se desarrolla entre sendas extremidades elaborando un gracioso doblez. El manto, que no cubre sus espaldas, se tercia de izquierda a derecha, recogiéndose los picos sobre el antebrazo siniestro. Los pliegues del mismo, dibujando líneas diagonales, se ciñen a la disposición cruzada de la prenda de forma suave. De igual modo son destacables los situados en la parte inferior del flanco izquierdo, conformando un aspecto trapezoidal a la figura.

El conjunto presenta algunos detalles metálicos en tonalidad plateada, como son los nimbos circulares que portan ambas figuras. También es destacable la característica vara de azucenas que se apoya en la muñeca derecha del varón. 
Fig. 4. Virgen del Pilar. Dependencias internas. Anónimo, 1612

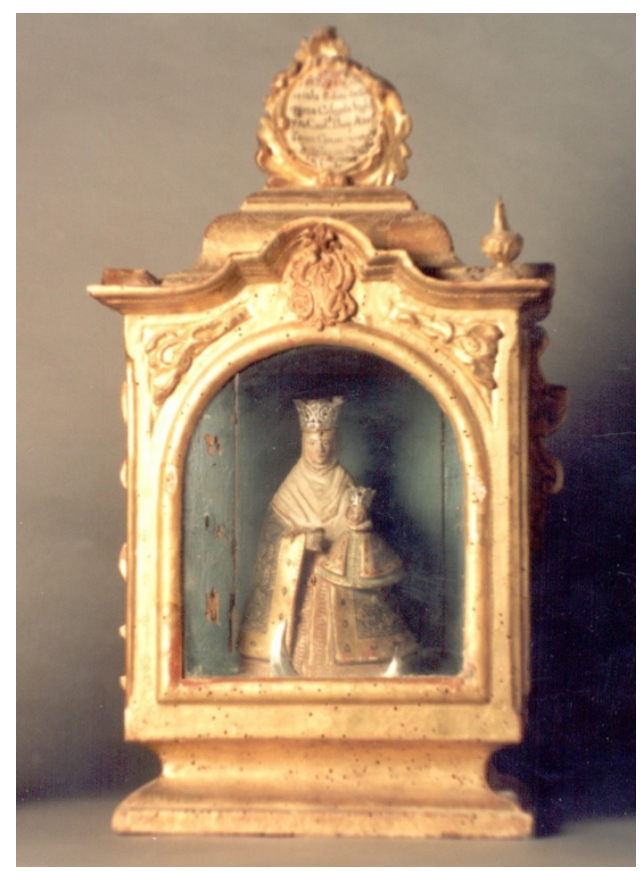

Finalmente, añadir que Pedro Tomás Valero en esta muestra de la iconografía josefina, se inspira claramente en los modelos de los Mora, toda vez que él mismo se había formado en el taller del menor de los hermanos, Diego, así como con uno de sus principales discípulos, Agustín de Vera Moreno. En este sentido, se aprecian notables similitudes en la disposición de las prendas con las imágenes de San José de la iglesia de Santo Domingo de Granada, así como con la talla de San José Artesano de Lucena.

Desde nuestro punto de vista, la talla más bella de la Inmaculada que conservamos en Granada de Duque Cornejo, es la que se conserva en el museo nuevo del Sacro Monte ${ }^{5}$. Previamente a esta ubicación, la escultura estuvo situada en la Capilla de Santiago de las Cuevas sacromontanas. Posteriormente, se trasladaría a la sacristía para, finalmente, terminar en su actual emplazamiento.

Tradicionalmente, desde un punto de vista meramente estilístico, los expertos siempre han relacionado la obra con el escultor sevillano. Documentalmente no se había encontrado ninguna referencia alusiva a ello. Tras un concienzudo vaciado de las Actas Capitulares de la Abadía del Sacro Monte en el verano de 2009, pudimos encontrar una leve reseña que informaba que un pariente del canónigo secretario don Luis Francisco de Viana, había donado una imagen de la Inmaculada Concepción de bulto redondo, de mano de Cornejo: "se propuso (...) que un devoto hania echo gracia a la Capilla de Nuestra Señora de las Cuevas, de una Imagen de bulto de la Concepción immaculada de mano de Cornejo con su retablo de talla dorado todo primoroso, y que quería se le hiziesse por este Cavildo escritura de obligación de no extraerla de el sitio de la Capilla de Nuestra Señora de las Cuevas a mano izquierda como entramos'.5. Uno de los detalles más llamativos de la obra es, sin lugar a dudas, la maravillosa peana sobre la que se dispone la figura mariana. De forma triangular invertida, se compone de numerosos ángeles, tanto de cuerpo entero, como de cabezas aladas. De entre los mismos, sobresale la acostumbrada luna en creciente, con sus puntas hacia abajo. En los querubes, se observan pequeños lienzos carmesíes que envuelven sus cuerpos, desarrollando un gracioso movimiento. Sobre los angelotes se ubica la imagen de la Virgen, erguida, uniendo sus manos a la altura del pecho, casi sin llegar a tocarse las yemas de sus dedos. Sus brazos se desplazan sutilmente hacia la

\footnotetext{
${ }^{5}$ Pita Andrade, 1974: 14; Sánchez-Mesa Martín, 1974: 55; 1998: 264; Martínez Justicia, 1996: 82; León Coloma, 2005: 264; AA. VV., 2006: 273; Peinado Guzmán, 2012.

${ }^{6}$ Actas Capitulares, VII, 2 de marzo de 1725, A.S.M., f. 55 r.
} 


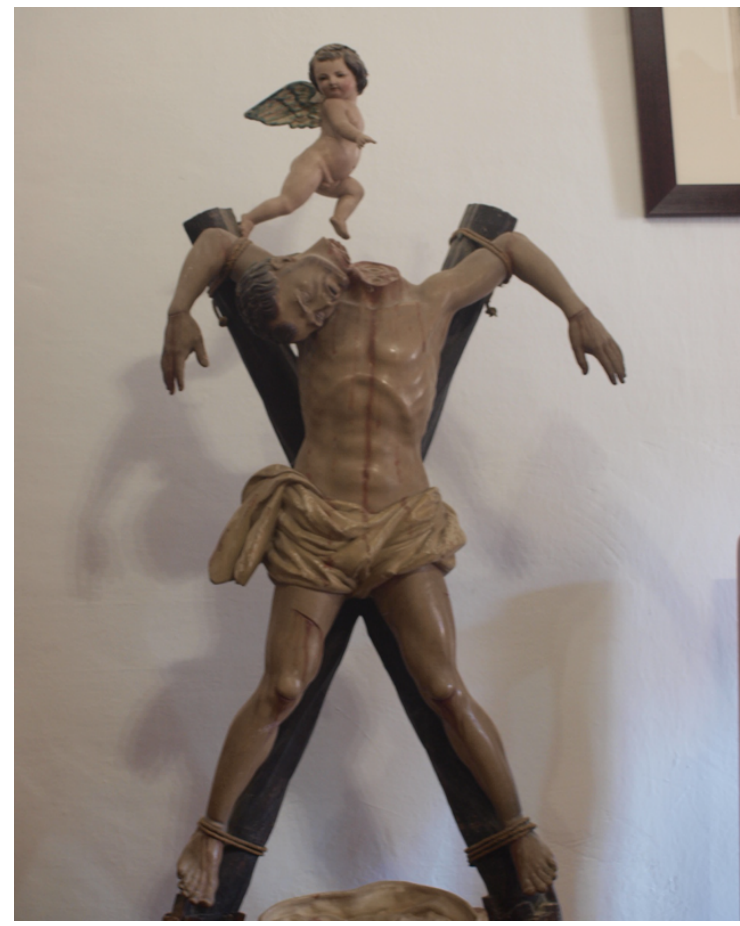

Fig. 5. San Serapio . de la Iglesia de la Abadía del Sacromonte. Plan de coro. Atribución a Diego de Mora, Siglo XVIII

derecha, de igual modo que su cabeza gira hacia el lado opuesto. En su rostro se aprecian los típicos rasgos ovalados y finos de Cornejo, su característica boca pequeña y apretada, o su nariz recta. Los ojos, destacadamente grandes, se enmarcan por unas cejas un tanto más matizadas. Resulta reseñable el curioso hoyuelo que se vislumbra en el cuello, no muy usual en los modelos que hasta ahora hemos analizado. El cabello, aun siguiendo las formas de modelado que acostumbra Cornejo, se aprecia algo más voluminoso. Largo, oscuro y menos alisado que en otros ejemplos suyos, se dispone sobre espaldas y algún mechón sobre el pecho. En esta muestra, sí se percibe el pelo ligeramente más trabajado.

La Virgen se presenta ataviada con las habituales prendas inmaculistas: túnica blanca de tonalidad cruda y manto azul. Asimismo, las holgadas mangas permiten ver otras inferiores, ceñidas al puño, de tonalidad rojiza. La vestimenta se sujeta en talle alto mediante cíngulo de similar coloración. Por el cuello de la vestimenta se distingue un mínimo encaje decorativo. El trabajo de plisados en los paños se muestra aparente. En la túnica se contemplan profundos, esbozando líneas verticales, y en ocasiones cortantes. Por su pierna izquierda, en cambio, se observa cómo dibujan líneas curvas. En las mangas y pecho se matizan los pliegues, apreciándose con más suavidad. La colocación del manto repite el tipo realizado por Cornejo para la talla de La Cartuja, pero a la inversa. Cayendo sobre sus espaldas, y generando un amplio y voluminoso vuelo, uno de sus picos, saliendo bajo el brazo derecho, se desprende sobre el mismo. De igual modo, el opuesto cae sobre la extremidad izquierda. En este sentido, resulta lucido cómo se marca este diseño del recogido de los ropajes alterno y contrario. Lo vaporoso del tejido determina que las ondulaciones, aunque profundas, se maticen y suavicen.

Curiosa resulta una imagen de la Virgen del Pilar que se conserva en las vitrinas de la escalera principal de la Abadía del Sacro Monte, y que fue regalada por el Cabildo de Zaragoza en 1612. La misma, bastante tosca en su ejecución, se encuentra en el interior de una urna con molduras doradas, y visible por tres de sus caras acristaladas. La talla nos ofrece una interpretación diferente a la clásica que acostumbramos a contemplar en el conocido modelo iconográfico. En esta ocasión se nos presenta vestida. Observamos a la Virgen de pie, sosteniendo al Niño, que se dispone en la parte derecha. Las formas de sendas figuras son notoriamente cónicas, debido a la deficiente resolución que utiliza para las vestimentas. Ambas imágenes se coronan con sus respectivas tiaras plateadas. 


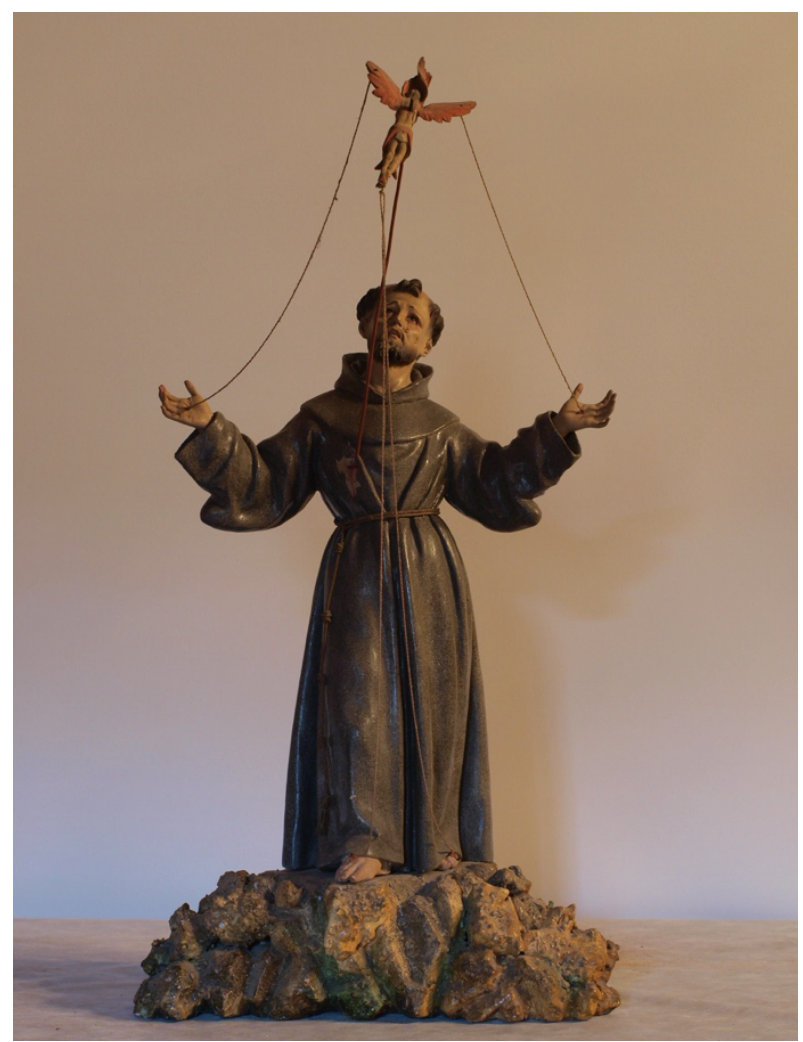

Fig. 6. Impresión de las llagas a San Francisco. . Museo Atribución al taller Diego de Mora, Siglo XVII- XVIII

La Virgen viste túnica blanca, que se decora con continuas incisiones horizontales a modo de ínfimo exorno. Se cubre, asimismo, con manto abierto a sendos lados, proporcionando a la talla un semblante triangular. La tonalidad del mismo es oscura, con elementos decorativos dorados, y galón dorado en el borde de la prenda particularmente ancho. De igual modo, María cubre su cabeza con velo blanco que se prolonga a la altura del pecho. Similares vestimentas observamos en el Niño, como se puede apreciar en el manto, prácticamente idéntico al de la Madre. La túnica, finalmente, es de tonalidad verde oliva y sobresale bajo el citado manto. Complementa la decoración de la imagen la típica media luna plateada a los pies de la misma.

Extremadamente dramática es la representación iconográfica de San Serapio en el momento de su martirio. Tiene sentido que en el Sacro Monte, lugar donde la tradición sitúa que fueron martirizados San Cecilio y sus compañeros, se contemple la figura de otro mártir, concretamente este fraile mercedario, que murió en 1240 cautivo de los sarracenos.

Se representa al santo una vez consumado su martirio, crucificado en aspa, y con la cabeza degollada y colgando sobre su pecho, unida aún a su cuello por un girón de piel. Queda asido a la cruz aspada atado con cordeles por los tobillos y codos, lo cual propicia que los brazos queden descolgados desde ese punto. En la parte superior, sobre la figura de San Serapio, vuela un angelito que debió portar una palma como atributo martirial. Su sujeción queda fijada solamente por su pie derecho sobre el extremo de la cruz. La disposición ascensional de la figura infantil hace que quede justo encima del santo, cerrando la composición en la parte superior. Creando el mismo efecto en la zona opuesta, aparece redoblado sobre el suelo el hábito mercedario del que fuera despojado el santo para su martirio.

Presenta un correcto tratamiento anatómico, con un especial estudio en el corte del cuello. Reproduce en detalle vías respiratorias, músculos y tendones sesgados, imprimiendo a la obra un mayor patetismo y drama, que acentúa el realismo extremo de la figuración martirial. A ella contribuyen también los ojos semicerrados a causa de la agonía. Los rasgos fisonómicos son los de un hombre enjuto y de marcada estructura ósea. Ojos rasgados, nariz fina, boca pequeña y definida en sus perfiles, circundada por bigote y barba incipientes, a base de un 
leve peleteado a punta de pincel, permiten relacionar esta talla con los modelos planteados por los hermanos Mora. El perizoma que cubre su desnudez se resuelve en menudos pliegues y la caída ampulosa de uno de los extremos del paño.

Vinculable en algunos aspectos a la gubia de un posible Ruiz del Peral, muy en la órbita aún de su maestro Diego de Mora, vendría a adelantarnos la forma de tratar la iconografía de la degollación, en su extrema realidad ${ }^{7}$, por parte de este artista. Puesto que es la primera vez que se aborda el estudio de esta imagen, quisiéramos plantear otra posible filiación, la de Pedro Tomás Valero. Las características formales que presenta, en especial en el rostro y manos permiten vincularlo al elenco de obras de este artista de mediados del XVIII granadino. Junto a la comparación estilística y formal con piezas documentadas del mismo, caso de los relieves que realizó para la iglesia del Sagrario de la capital granadina: Evangelistas del púlpito y titulares de los retablos de San Cecilio y San Juan de Dios. Su formación y colaboración con Agustín de Vera Moreno, formado a su vez con Diego de Mora, le permitieron conocer y continuar los modelos de este último de manera bastante fidedigna en algunos aspectos puntuales antes referidos. Visto esto, y conociendo la presencia de otras obras de su mano en la Abadía del Sacro Monte ${ }^{8}$, nos reafirmamos en dicha atribución.

Singular representación escultórica encontramos de la Estigmatización de San Francisco de Asís podemos encontrar en el museo sacromontano. Se trata de una talla de unos $50 \mathrm{~cm}$. aproximadamente, realizada en madera tallada y policromada. Se representa en el momento en que recibe los estigmas de la pasión de Cristo en su cuerpo, procedentes de la figura de Jesús revestida de serafín. Para ello se muestra al santo en pie, descalzo sobre una amplia superficie rocosa, con los brazos extendidos y alzados en forma de cruz, y la cabeza reclinada para elevar su mirada el cielo. Viste el santo túnica talar franciscana, con capucha y ceñida a la cintura por un cordel con los típicos cinco nudos que caracterizan al hábito de su orden. Esta prenda se resuelve con un profundo pliegue central, que le otorga cierto dinamismo a la figura dentro de la quietud de la escena. Del mismo modo, destacan en la prenda los abultados pliegues de las mangas, propios del atuendo de la rama capuchina de los franciscanos de la época, y que el escultor debió tomar como referente. El plegado textil es siempre amplio y de cierta suavidad. Su rostro es el de un hombre joven, enjuto, de estructura facial muy marcada, en especial los pómulos. Barba poco poblada y cabellera recortada a modo de "coronilla" circundando el cráneo. Es un rostro que conjunta la gran belleza de formas con un sentido drama y una profunda espiritualidad. Todo ello conseguido por un marcado detallismo de los rasgos, caso de la disposición ondulada de las cejas. Algunos de estos rasgos son los que nos permiten valorar la autoría de esta imagen en el taller de los hermanos Mora, a caballo entre los siglos XVII y XVIII. El marcado enarcado de las cejas, el fruncimiento del ceño, ojos grandes y algo rasgados, nariz fina, así como la manera de resolver los pómulos y sobre todo el modelado de la boca, nos llevan a esta filiación. Presenta también la imagen un minucioso trabajo de talla en las manos y los pies.

La escena se completa con la mencionada figura cristífera. Aparece Jesús en posición de estar crucificado, sin cruz a sus espaldas, envuelto en las seis alas características de la categoría angélica de los Serafines. Dos de las alas se elevan sobre su cabeza, cerrándose en torno a ésta a modo de capucha o resplandor; otras dos se extienden tras los brazos y las dos restantes se cierran sobre las piernas envolviéndolas, conformando así un símil con el árbol de la cruz. Este elemento resulta de gran atractivo por su disposición dentro del conjunto escultórico. Dado que representa una aparición, queda suspendido en el aire a mayor altura, asido a la imagen del santo por una varilla que une ambos costados. Del mismo modo se unen las llagas de ambas figuras mediante finos cordeles tintados en rojo, que al igual que la mencionada varilla, representan la sangre de Cristo que impregnó sus llagas en el cuerpo de

\footnotetext{
7 También podemos encontrar un modelo más moderado de abordar este tipo de martirio, con una simple incisión en el cuello de la figura cuando se trata de dejar constancia de la ejecución en representaciones vivas del personaje.

${ }^{8}$ Para la iglesia abacial realizó las imágenes de la Inmaculada Concepción y San José, de los retablos colaterales del crucero, como previamente se ha mencionado.
} 
Fig. 7. San Antonio de Padua. . Museo Atribución Torcuato Ruiz del Peral, Siglo XVIII

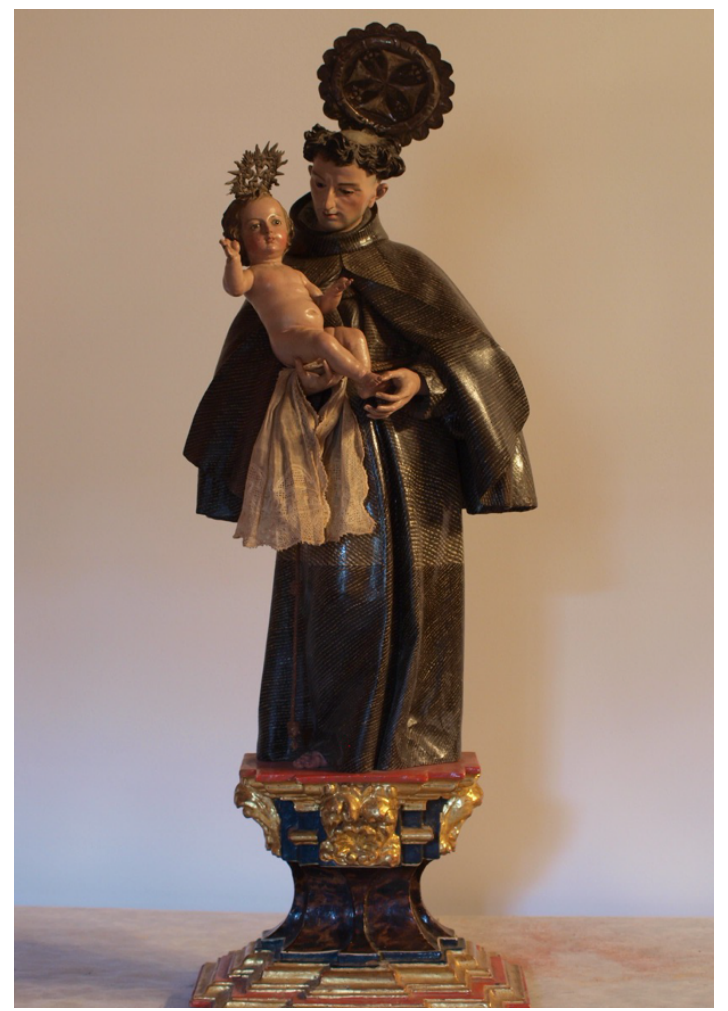

San Francisco. Son recursos expresivos que otorgan al conjunto escultórico un mayor dramatismo, y ayudan a resolver la escenografía deseada, más propicia de realizarse en pintura que en bulto redondo, dada su complejidad representativa.

Otros recursos plásticos que imprimen mayor realismo a la imagen son el empleo de materia vegetal en el cordel de la túnica, así como los ojos de cristal que muestran una auténtica sensación de ojos enrasados en lágrimas por el dolor físico y el gran gozo espiritual que debió experimentar Francisco de Asís.

Relacionable con esta imagen es la que se venera en el templo conventual de Santa Isabel la Real, en este caso el santo se dispone arrodillado, o más parecido por su posición el que se encuentra a tamaño cercano al natural, en la parroquia de la Encarnación de Loja, con gran cercanía en el tratamiento del hábito. Sin embargo, el que mayor similitud presenta en la resolución estética del rostro es el que se venera en la iglesia de San Francisco de Priego de Córdoba. Pieza que atribuimos directamente a Diego de Mora, y a cuyo taller, por similitud estilística, también vinculamos está de la Abadía granadina.

La efigie de San Antonio de Padua que se puede contemplar en el museo sacromontano es un magnífico ejemplo de la valía artística de las tallas que atesora este espacio. Es una imagen de pequeño formato, $50 \mathrm{~cm}$. centímetros aproximadamente, que representa al santo portugués en su habitual iconografía de la aparición del Niño Jesús en una casa donde se hospedaba. El santo aparece erguido con el divino infante en sentado sobre su mano derecha, la izquierda la acerca hacia el mismo cogiéndole el pie, mientras le dirige su mirada. Este gesto obliga a disponer la cabeza girada hacia el niño, y levemente inclinada hacia la izquierda. El santo muestra un rostro enjuto y estilizado, de marcada estructura ósea, con rasgos fisonómicos muy particulares como nariz fina y alargada, boca pequeña y algo prominente, ojos rasgados. Pero si algo llama poderosamente la atención es el minucioso trabajo de talla del cabello, que da por resultado un airoso juego de volúmenes alrededor de la cabeza, a base de finos mechones ensortijados. Similar en trabajo pueden calificarse las manos, de dedos finos y estilizados, quebrados y angulosos, barroquismo de las formas más acusado en la mano sobre la que sienta el niño y más delicado en la que acerca al pie. 
El Niño extiende sus brazos hacia adelante, adivinamos que en actitud de bendecir, ya que la ausencia de la totalidad de sus dedos nos impiden afirmarlo. Tallado en su totalidad se presenta desnudo, con un cuerpo rollizo, de voluminosa testa, frente despejada y trabajado cabello dispuesto en mechones.

Viste San Antonio túnica de estameña marrón, que trasluce el movimiento corporal a través del plegado, en especial por el amplio pliegue que la centra en la delantera y trasera. Viste también capuz y capa corta de amplio vuelo, característico empleo del hábito cubierto con media capa que en otras obras relacionadas con el autor no aparece. Este tipo de soluciones para el hábito franciscano se viene rastreando en la escuela granadina de escultura desde el siglo XVII, en especial desde la producción de Alonso Cano y Pedro de Mena. Si bien los pliegues más trabajados y los amplios vuelos en la capa son recursos más propios de los Mora y Peral.

En este caso nos atrevemos a aseverar la atribución de esta pieza al escultor Torcuato Ruiz del Peral. Las formas empleadas para resolver el cabello, los rasgos faciales y las manos del santo, así como el divino infante al completo, nos llevan a ello. Se pueden apreciar bastantes similitudes con otras piezas homónimas documentadas del mismo autor, caso del desaparecido de Purullena, o el San Antonio de la iglesia Mayor de Baza, ambos desaparecidos ${ }^{9}$. En especial con este último, resalta el mimetismo compositivo tanto de la figuras del santo como de la de los niños. Con ellos se asemeja, sobre todo, en la solución ensortijada adoptada para el cabello, también en la estructura facial y la mencionada disposición en pliegues de la túnica. Innegable es, a todas luces, la deuda que esta imagen mantiene con los modelos de Diego de Mora, maestro de Ruiz del Peral. La obra sacromontana mantiene vivos algunos grafismos propios del menor de los Mora, caso de la posición de las manos, una para alojar la figura del infante y otra en acercamiento. Pero sobre todo se puede apreciar la evolución del modelo adoptado por Mora para esta iconografía y otras similares, desligándose en parte de lo que antes hiciera Pedro de Mena. Esta obra que tratamos manifiesta la continuidad evolutiva y personalizada que lleva a cabo Ruiz del Peral, y que se puede ilustrar perfectamente si tomamos como precedentes las dos siguientes obras: San Antonio, de la Basílica de las Angustias, obra tradicionalmente relacionada con José de Mora, aunque cada día gana fuerza su inclusión en el catálogo de Diego de Mora. Y como paso intermedio, una pieza que se vincula por primera vez a las gubias de Ruiz del Peral, el San Antonio de Padua de la parroquial de Dúrcal. Muy cercana aún a su maestro en cuanto al rostro, cabello y composición, pero que comienza a indicar sus características propias en la figura del Niño y en la curvatura o contraposto que imprime al santo, como ocurre con el mencionado y malogrado de Baza.

Es de resaltar también la peana sobre la que se asienta la imagen. Es una pieza de planta cuadrada y sección curva en su altura, policromada a imitación de carey. Se decora con placas recortadas y sobre ellas golpes de talla dorada.

La pieza que presentamos a continuación es un tanto particular dentro del elenco que estamos tratando. Se trata de la única pieza de vestir que sacamos a la luz, la imagen de María Dolorosa situada en el espacio conocido como "Plan de coro". Obra de candelero, de unos $60 \mathrm{~cm}$ aproximadamente, que representa a María erguida en actitud doliente. Tiene la cabeza inclinada hacia abajo y las manos en posición oferente, aunque en la actualidad no muestra ningún atributo en ellas. El rostro está realizado con gran destreza, mostrando claramente un detalloso preciosismo en sus facciones. Ojos rasgados, cejas enarcadas que indican un ceño fruncido y acentúa el dramatismo de la expresión. Nariz fina y boca pequeña muy bien definida en sus perfiles. Las manos manifiestan también una gran labor de talla, a pesar de sus reducidas dimensiones. Estos rasgos permiten encuadrar la imagen en la escuela granadina de entre siglos XVII y XVIII, en especial dentro de la producción de la saga de los Mora. Muestra en su rostro esta imagen características propias de estos artistas.

${ }^{9}$ Lázaro Damas, 2008: 92. 


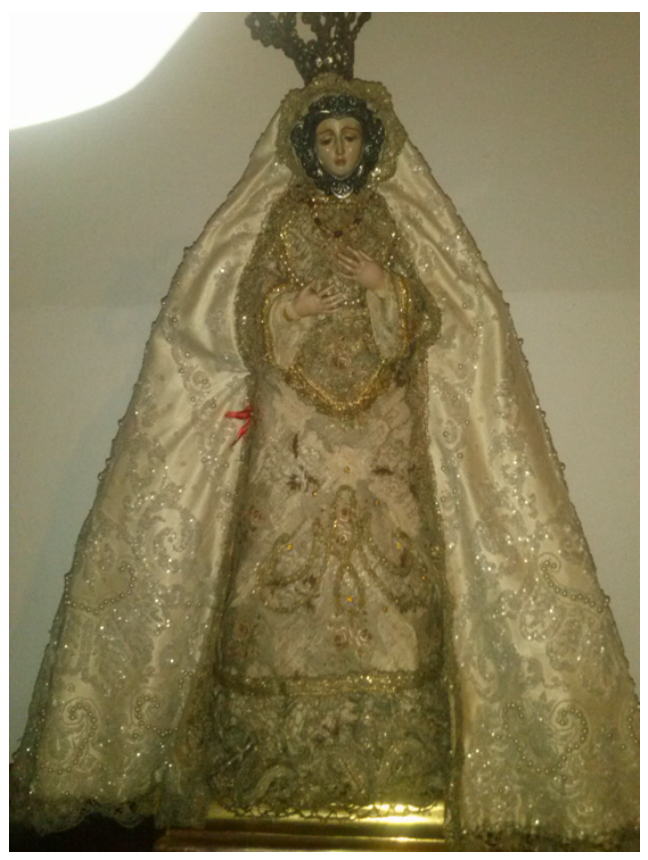

Fig. 8. Dolorosa. . Plan de coro Atribución Diego de Mora, Siglo XVIII

La Virgen viste en la actualidad saya y manto de color crudo, con aplicaciones y pedrería. Destaca de su ajuar el rostrillo en plata, posiblemente del siglo XVIII, y la corona imperial. Muestras de que pudo gozar de una pujante devoción en tiempo pasados.

A la vista de este análisis estilístico, se puede relacionar esta imagen con la que los documentos citan como imagen de Mora bajo la advocación del Consuelo.

"Yt. ley un mem" del Hmo Joseph de $\mathrm{S}^{\mathrm{n}}$ Antonio / en qe por especiales motivos, qe referencia tener, pedia liza para poner / en mas culto y reverencia la Milagrosa Ymagen qe esta al pie de la Questa frente del Carmen de las Rejas / Haciendo en el sitio en qe esta un hermita u oratorio en qe / poner la dha Ymagen y asimismo una muy devota de $\mathrm{Nra} / \mathrm{Ss}^{\mathrm{ra}}$ del Consuelo $\mathrm{q}^{\mathrm{e}} \mathrm{el} \mathrm{Herm}^{\circ}$ avia solicitado, echura de / Mora, y que en todo esto no tendria el Cavdo Gasto al- / (fol. 49 v.) guno..."10.

En el cabildo de 5 de agosto de 1728, el hermano José de San Antonio, presumimos que de la orden francisca por el sobre nombre que empleaba, solicitó permiso para colocar en la futura ermita una imagen de la Virgen, obra de uno de los Mora. Para esta fecha sólo quedaba vivo el menor de la saga, Diego, presto a morir al año siguiente. Por tanto, deducimos que la imagen que se solicita sería ejecutada unos años antes y posible obra del citado Diego de Mora. No hay constancia de la construcción de la citada ermita, pero sí se mantiene un pequeño altar en dicho lugar, presidido por el lienzo de un Ecce-Homo. Dada la advocación pasionista del titular cristífero, suponemos que la imagen mariana con la que se pensaba acompañar debiera ser también dolorosa. Basándonos en los términos expuestos, así como en el análisis estilístico, concluimos que la imagen de Mora que se cita bien pudiera ser la Dolorosa que se encuentra en la ante sala Capitular.

Siguiendo con la misma iconografía traemos a la luz la imagen de la Dolorosa que se venera presidiendo una de las capillas de las Santas Cuevas. Se trata de una obra de talla en madera y telas encoladas que representa a María erguida, con las manos cruzadas sobre el pecho. Viste túnica blanca, ceñida por la cintura con un fino cíngulo marcando los pliegues de la prenda. Se cubre con manto negro orlado por una cenefa dorada con motivos vegetales y por un encaje textil. El manto cae desde la cabeza adaptándose al cuerpo, con mayor volumetría al abrirse sobre los brazos. El vuelo sobre la cabeza enmarca y cobija el rostro, a

10 Actas capitulares, VII, A.S.M., ff. 149 r. y vto. 
Fig. 9. Dolorosa. . Santas cuevas Siglo XVIII

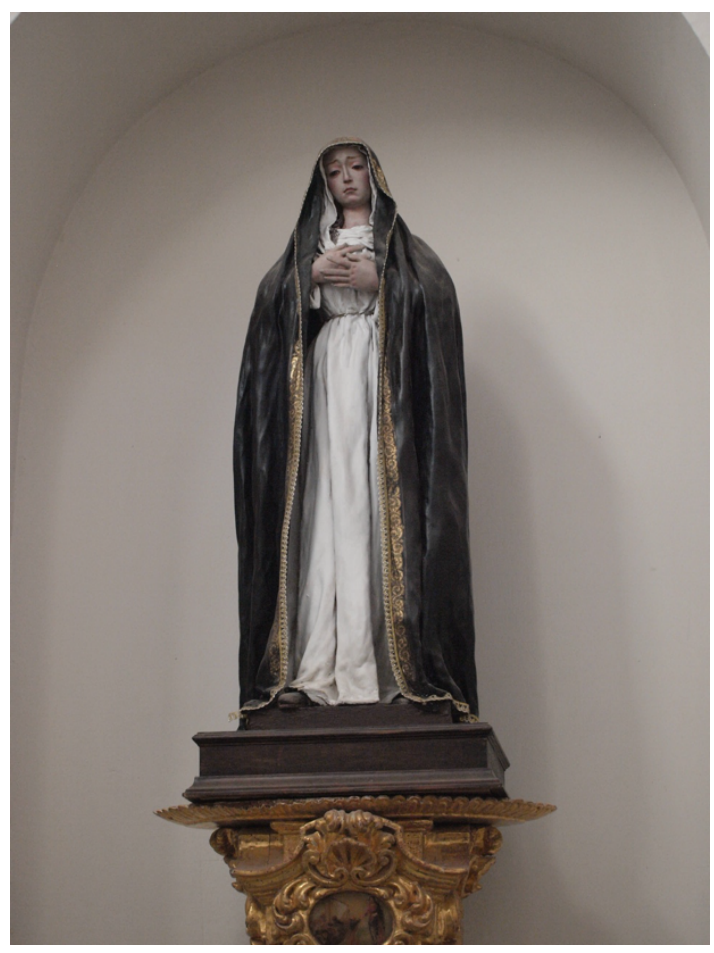

la vez que proyecta sombra sobre el rostro. Este recurso lumínico intensifica la sensación de intimidad y soledad de la imagen, muy empleado en la escuela granadina de escultura, especialmente desde Pedro de Mena y encumbrado por José de Mora en su Virgen de los Dolores de los Filipenses ${ }^{11}$.

Un rostro alargado, de perfil bastante definido, con grandes ojos y cejas de marcada ondulación por el ceño fruncido, y en especial la boca cerrada y de perfiles bien marcados, permiten transmitir un sentimiento de pena compungida. Un intimismo que se acentúa con el mencionado recurso del manto volado. Las manos, sin embargo, no parecen tan bien resueltas. Esta serie de estilemas nos permiten dictaminar una filiación artística, sin duda, deudora del buen hacer de los Mora. Hay que tener en cuenta que la popularidad que alcanzó, tanto el modelo de Dolorosa de manos sobre el pecho, como los rostros dolientes ejecutados por los hermanos Mora, llevaron a otros artistas a recoger este prototipo a lo largo de todo el siglo XVIII. Cierto es que la imagen presenta algunas similitudes de rostro con la Dolorosa que se venera en la iglesia parroquial de Santa María Magdalena de Granada, también con la misma filiación artística. Siguiendo el mismo modelo compositivo, aunque de mayor calidad artística, encontramos otra Dolorosa en la clausura del Monasterio de la Santísima Encarnación de Carmelitas Descalzas, en la misma ciudad de la Alhambra.

Conocemos un dato que posiblemente se pueda relacionar con esta imagen de las Cuevas. En 1746 se registra la solicitud de traslado de una dolorosa que se veneraba en la Santas Cuevas a la iglesia, para su mejor contemplación.

"Yten leiron memorial en que don Joseph Sanchez pedia licencia para traerse a la Yglesia i ponerse en altar donde tenga mas culto una imagen de escultura de los Dolores que el Maestro Velez ha mudado en la cuevas a sitio donde careze de luzimiento y veneración, lo que oído se acordó que el dicho Joseph Sanchez trajese a la Yglesia la dicha imagen y en ella se coloque en el altar donde convenga" 12

\footnotetext{
${ }^{11}$ Hoy advocada Soledad del Calvario, en la iglesia parroquial de San Gil y Santa Ana.

12 Actas capitulares, VII, 30 de diciembre de 1746, A.S.M., f. 496 r.
} 


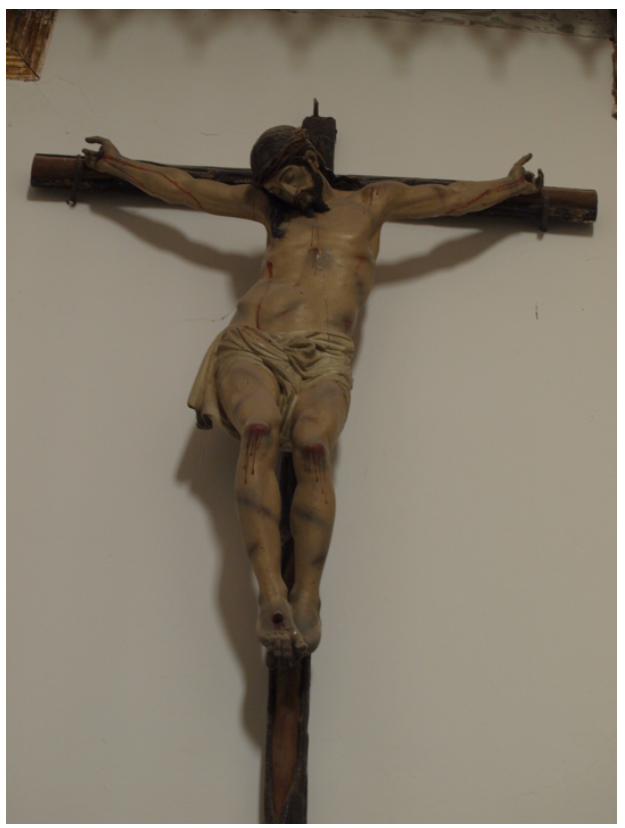

Fig. 10. Cristo Crucificado. . Santas cuevas Anónimo.

La imagen parece localizarse de nuevo en las cuevas ya en el siglo $\mathrm{XX}^{13}$. Por los grafismos plásticos que presenta la imagen de las Santas Cuevas, y con este dato, nos atrevemos a fechar su ejecución en el segundo cuarto del siglo XVIII.

Continuando en el espacio de las Santas Cuevas encontramos un interesante Crucifijo, dispuesto junto a otras dos piezas de San Juan y una figura femenina ${ }^{14}$, queriendo simular un Calvario. Se trata de una obra de tamaño inferior al natural, realizada en madera policromada. Destaca principalmente por la llamativa torsión helicoidal de su cuerpo, generado por el desplazamiento de las caderas hacia su derecha. La cabeza queda caída hacia el mismo, lo que visual y compositivamente provoca una línea serpenteante muy afecta a las formas manieristas. Este modelo recuerda a los crucifijos que plasmaran los pinceles de El Greco o Miguel Ángel Buonarotti, y a la talla que Marcos Cabrera legara a la estatuaria procesional sevillana. Aunque en su gran mayoría representan a Cristo expirante, mientras la pieza que tratamos es ya un Cristo muerto.

En cuanto al rostro, presenta una barba poblada, con terminación bífida puntiaguda. El cabello se dispone caído hacia atrás, dejando visible el pabellón auricular izquierdo, mientras que en el lado opuesto cae un mechón sobre el pecho, con el extremo algo rizado. El bigote arqueado se inicia desde fuera del surco nasolabial, de menor a mayor. Estos estilemas, junto a una anatomía de blando modelado, algo más desarrollada en brazos y cuello por la tensión generada en ellos, recuerdan a las imágenes crucíferas de la segunda mitad del siglo XVI, caso concreto al del Calvario del Sagrario granadino. Distando de esta tipología por su acusada contorsión corporal, cierto es que la forma de resolver el mechón sobre el pecho recuerda a los detalles de la obra de Pablo de Rojas. Posiblemente estemos ante una obra que mantiene los resabios de imágenes renacentistas, con algunos matices tardo-góticos en rasgos muy concretos, introduciendo ya innovaciones de un barroco incipiente tanto en dinamismo como en naturalismo. Estilemas que nos remitirían a un periodo de entre siglos, XVI y XVII.

Alojado sobre la mesa de altar de la capilla de San Dionisio, encontramos una interesante pieza del elenco escultórico sacromontano, que se mantiene desconocida debido a lo recóndito de su ubicación. Se trata de una imagen de Cristo en la cruz, de pequeño formato. Presenta un canon corporal estilizado, con cabeza pequeña y amplias extremidades. Un conjunto anatómico muy bien trabajado, a pesar de lo reducido de sus dimensiones. Gira la

\footnotetext{
13 Gallego y Burín, 1997: 365.

${ }^{14}$ Estas dos imágenes quedan fuera del estudio a causa de su desigual calidad artística con el Crucificado.
} 


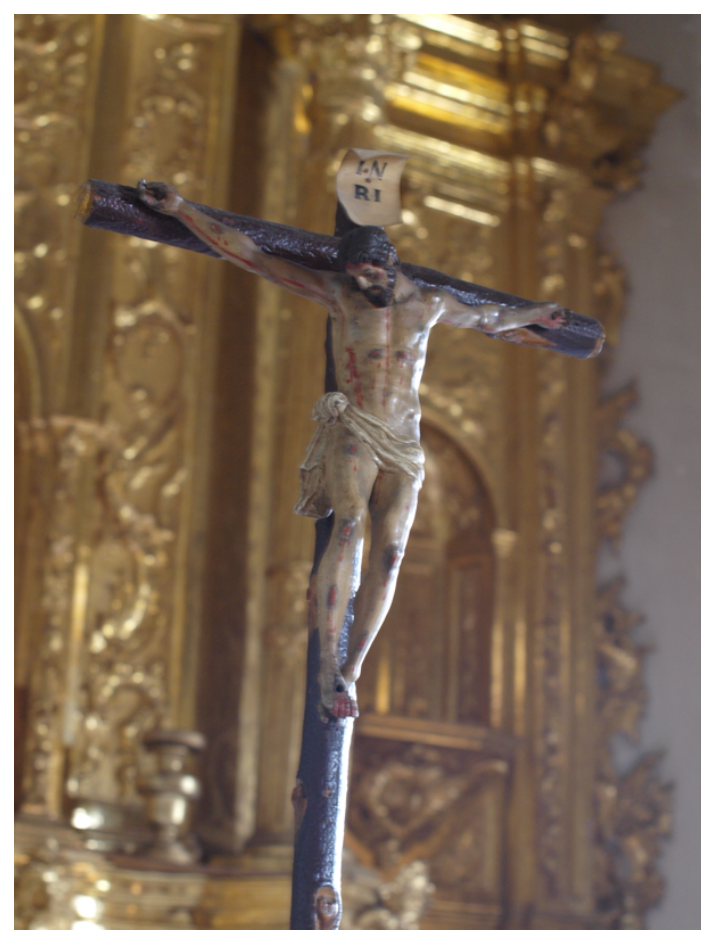

Fig. 11. Cristo Crucificado. . Capilla de San Dionisio Aeropagita. Anónimo. Siglo XVII

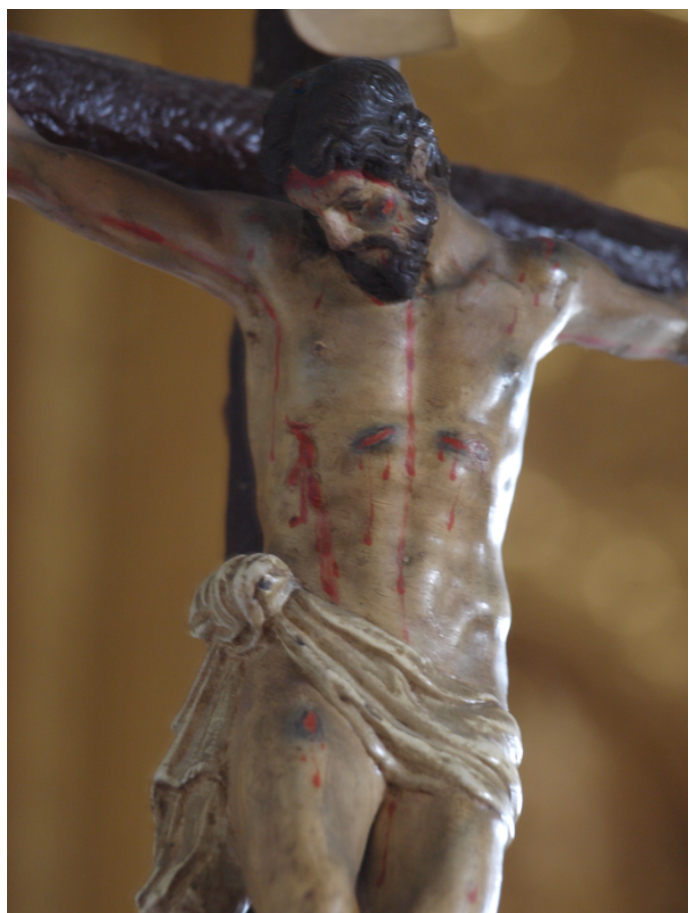

Fig. 12. Cristo Crucificado. (Por menor). Capilla de San Dionisio Aeropagita. Anónimo. Siglo XVII.

cabeza hacia su derecha, dejándola caer sobre su hombro y acercando la barbilla al pecho. Los rasgos faciales aparecen bastante alterados por intervenciones posteriores, especialmente repintes. Sin embargo, el tratamiento del cabello sí mantiene visible el trabajo de talla original. Se dispone partido en dos, sobre la cabeza, trabajado en finos mechones, que se ondulan de forma destacada sobre la frente. Dichos mechones se prolongan y voltean sobre la oreja izquierda, dejando visible tanto el pabellón auditivo como el cuello en toda su extensión. Ello permite también trabajar la tensión muscular de esta zona. La barba y el bigote aparecen también elaborados a base de finos, prolongados y ondulados trazos de gubia.

El mencionado giro de la cabeza hacia la derecha, obliga a su vez a adelantar el hombro opuesto, sacándolo por tanto del plano de la composición. Dos elementos que otorgan al conjunto de la figura dinamismo, a pesar de lo estático o rígido de su esquema compositivo básico, pues se observa cómo tronco y piernas trazan una cruz casi perfecta con la linealidad de los brazos. Otro elemento que ayuda a romper dicha rigidez en su zona central es el paño de pureza, conformando una diagonal desde la parte superior de la cadera derecha hasta la inferior de la opuesta, dejando visible el trabajo de la zona inguinal. El perizoma se resuelve mediante varios pliegues paralelos con poco movimiento, anudándose de manera ampulosa sobre la cadera derecha, desde donde cae de forma zigzagueante.

Las características plásticas que nos presenta esta imagen coinciden perfectamente con las que se desarrollaron en la iconografía del crucificado en los inicios del naturalismo escultórico en Granada. Hablamos del último cuarto del siglo XVI y principios del XVII, con nombres como Pablo de Rojas y Alonso de Mena, entre otros. La resolución anatómica, giros compositivos, la disposición y forma de trabajar el cabello permiten acercar la atribución de esta talla al imaginero alcalaíno Pablo de Rojas. Quien también trabajara para la casa la Virgen del Rosario del templo abacial ${ }^{15}$.

${ }^{15}$ López-Guadalupe, 2010: 171 -172. 
Bibliografía

AA. VV.: Guía artística de Granada y su provincia (vol. I). Sevilla: Fund. José Manuel Lara. (2006).

Antolínez de Burgos, J.: Historia eclesiástica de Granada. Granada: Universidad de Granada. (1996).

Barrios Aguilera, M.: "Moriscos y cristianos en el orto de la Granada Moderna". En: Martínez Medina, Francisco Javier (ed.) (2000): Jesucristo y el Emperador cristiano. Córdoba: CajaSur. (2000).

Barrios Aguilera, M.: "Pedro de Castro y los plomos del Sacromonte. Invención y paradoja. Una aproximación crítica”. En: Barrios Aguilera, Manuel y García Arenal, Mercedes (eds.) (2006): Los plomos del Sacromonte. Invención y tesoro. Valencia: Universitat de Valencia. (2006).

Benítez Sánchez-Blanco, R.: "De Pablo a Saulo: traducción, crítica y denuncia de los Libros plúmbeos por el P. Ignacio de las Casas, S. J.”. En: Barrios Aguilera, Manuel y García Arenal, Mercedes (eds.) (2006): Los plomos del Sacromonte. Invención y tesoro. Valencia: Universitat de Valencia. (2006).

Bermúdez de Pedraza, F.: Historia eclesiástica de Granada. Granada: Universidad de Granada. (1989).

Bonet Correa, A.: "Entre la superchería y la fe: el Sacromonte de Granada". En: Historia 16, 61, Madrid, (1981) pp. 43-54.

Cabanelas, D.: El morisco granadino Alonso del Castillo, Granada: Patronato de la Alhambra y Generalife. (1965).

Cabanelas, D.: "El Sacromonte punto de confluencia doctrinal entre Islam y la Cristiandad". En: La Abadía del Sacromonte. Exposición artístico-documental. Estudios sobre su significación y orígenes. Granada: Universidad-Secretariado de Publicaciones, (1974), pp.34-40.

Caro Baroja, J.: Las falsificaciones de la Historia en relación con la de España. Barcelona: Seix Barral. (1992).

Centurión, A.: Información para la historia del Sacro monte llamado de Valparaíso y antiguamente ilipulitano, junto a Granada, donde parecieron las cenizas de S. Cecilio, S. Tesiphón y S. Hiscio, discípulos del apóstol, único patrón de las Españas, Santiago, y otros santos discípulos dellos y sus libros escritos en láminas de plomo. Parte primera, Granada. (1632).

Centurión, A.: Traducción de los libros en Arabe escritos en laminas de plomo que con las reliquias de los santos Cecilio, Hiscio y Tesiphon, discípulos del apóstol Santiago sehallaron guardados desde aquel tiempo debajo detierra cerca de Granada año de 1595. Hazíala con summa fidelidad y diligencia consus intérpretes Adan Centurión, marques de Estepa, S. I., s. n.

Gallego y Burín, A.: Granada. Guía artística e histórica de la ciudad. Granada: Comares. (1982).

Gallego y Burín, A.: El Barroco granadino. Granada: Universidad de Granada. (1987).

Gómez Román, A.Ma.: "Torcuato Ruiz del Peral y el devenir de la escultura en Granada hasta mediados del siglo XIX". En: Boletín del Centro de Estudios "Pedro Suárez". Monográfico Torcuato Ruiz del Peral (1708-1773). Vol. 1, nº 21 Guadix, .(2008), pp. 327398.

Hagerty, M.J.: Los libros plúmbeos del Sacromonte. Madrid: Editora Nacional. (1980).

Heredia Barnuevo, D.N.: Místico ramillete. Vida de D. Pedro de Castro, fundador del Sacromonte. Granada: Universidad de Granada. (1998). 
Justicia Segovia, J.J.: “La iconografía del Sacromonte”. En: Martínez Medina, Francisco Javier (ed.) (2000): Jesucristo y el Emperador cristiano. Córdoba: CajaSur, (2000), pp. 645-648.

Lázaro Damas, $\mathrm{M}^{\mathrm{a}}$ S.: "Consideraciones en torno a la obra y clientela de Torcuato Ruiz del Peral en Baza". En: Boletín del Centro de Estudios "Pedro Suárez" Monográfico Torcuato Ruiz del Peral (1708-1773), Vol. 1, nº. 21, Guadix, (2008), pp. 77-100.

León Coloma, M.A.: "La Inmaculada Concepción en la escultura granadina". En: Martínez Medina, Franciscojavier et al. (eds.) (2005): A María no tocó el pecado primero. La Inmaculada en Granada. Córdoba: Publicaciones obra social y cultural CajaSur, (2005), pp.245-267.

López-Guadalupe Muñoz, J.J.: "Escultura y escultores en Granada en la época de Ruiz del Peral. Modelos, talleres y síntesis evolutiva", en: Boletín del Centro de Estudios "Pedro Suárez" Monográfico Torcuato Ruiz del Peral (1708-1773), Vol. 1, n. 21, Guadix, (2008), pp. 291-326.

López-Guadalupe Muñoz, J.J.: "Pablo de Rojas, encrucijada de las escuelas andaluzas". En: Gila Medina, Lázaro (ed.): La escultura del primer naturalismo en Andalucía e Hispanoamérica (1580-1625). Madrid: Arco Libros, (2010), pp.139-174.

López-Muñoz Martínez, I.N.: Torcuato Ruiz del Peral. Escultor imaginero de Exfiliana. III centenario de su nacimiento, (1708-2008). Guadix: Ayuntamiento de Valle del Zalabí y Comarketing Wadi S.L. (2008a).

López-Muñoz Martínez, I.N.: “Aspectos inéditos en la creación artística de Torcuato Ruiz del Peral: hacia una nueva estética concebida desde el sincretismo formal y el fasto cromático". En: Boletín del Centro de Estudios "Pedro Suárez" Monográfico Torcuato Ruiz del Peral (1708-1773), Vol. 1, nº. 21, Guadix, (2008b) pp.55-76.

Martínez Justicia, $\mathrm{M}^{\mathrm{a}} \mathrm{J} .:$ La vida de la Virgen en la escultura granadina. Madrid: Fundación Universitaria Española. (1996).

Martínez Medina, F.J.: "El Sacromonte de Granada y los discursos inmaculistas postridentinos", en: Archivo Teológico Granadino, 59, Granada, (1996), pp. 5-57.

Martínez Medina, F.J.: "El Sacromonte de Granada y los sacromontes: mito y realidad", en: Proyección, 44 Granada, (1997), pp.83-94.

Martínez Medina,F.J.: "El Sacromonte de Granada, un intento de reinculturación entre la guerra de los moriscos y su definitiva expulsión”, en: Chronica Nova, 25, Granada, (1998), pp.349-379.

Martínez Medina, F.J.: "Los libros plúmbeos del Sacromonte de Granada". En: Martínez Medina, Francisco Javier (ed.) (2000): Jesucristo y el Emperador cristiano. Córdoba: CajaSur, (2000), pp.619-644.

Martínez Medina, F.J.: "Los hallazgos del Sacromonte a la luz de la Historia de la Iglesia y de la teología católica”. En: Al-Qantara, vol. 23, n. 2, Madrid, (2002), pp.437-475.

Martínez Medina, F.J.: "El Sacromonte de Granada: impulsor de la Inmaculada Concepción en la Contrarreforma". En: Martínez Medina, Francisco Javier (ed.): A María no tocó el pecado primero. "La Inmaculada en Granada". Córdoba: CajaSur, (2005), pp. 119-155.

Martínez Medina, F.J.: "Los hallazgos del Sacromonte a la luz de la Historia de la Iglesia y de la teología católica". En: Barrios Aguilera, Manuel y García Arenal, Mercedes (eds.) (2006): Los plomos del Sacromonte. Invención y tesoro. Valencia: Universitat de Valencia, (2006), pp. 79-112.

Peinado Guzmán, J.M.: Controversia teológica, devoción popular y expresión artística: La Inmaculada Concepción en Granada. Tesis doctoral inédita. Departamento de Historia del Arte, Universidad de Granada, (2012).

Pita Andrade, J.M.: Museo del Sacromonte. Col. Guías de los museos de España. Vol. 20. Madrid: Ministerio de Educación Nacional, Dirección General de Bellas Artes. (1964).

Ramos, J.: El Sacro Monte de Granada. Madrid: Fortanet. (1883). 
Royo Campos, Z.: El insigne Colegio del Sacromonte y la Universidad de Granada. Granada: Prieto. (1951). Royo Campos, Z.: Albores del Sacromonte. Granada. (1958).

Royo Campos, Z.: Don Pedro de Castro, caudillo insigne del concepcionismo en España. Granada, Arzobispado de Granada, (1954).

Royo Campos, Z.: Reliquias martiriales del Sacromonte. Granada: Abadía del Sacro Monte. (1960).

Sánchez-Mesa Martín, D.: "Aportaciones al estudio de la escultura religiosa en el Sacromonte”. En: La Abadía del Sacromonte. Exposición artístico-documental. Estudios sobre su significación y orígenes. Granada:

Universidad-Secretariado de Publicaciones, (1974), pp.53-61.

Sánchez-Mesa Martín, D.: "El arte del Barroco. Escultura, pintura y artes decorativas". En: Historia del Arte en Andalucía. vol. VII). Sevilla: Gever. (1998).

Serna Cantoral, D. de la: Vindicias catholicas granatenses: relacion breue de las reliquias que se hallaron en la ciudad de Granada en una torre antiquissima, y en las cauernas del Monte Illipulitano de Valparayso cerca de la ciudad, sacado del processo y aueriguaciones, q cerca dello se hizieron. León de Francia. (1706). 